\title{
Tri-Band Slot-Loaded Microstrip Antenna for Internet of Things Applications
}

\author{
Shereen Mohamed-Refaat ${ }^{1}$, Ahmed Abdelaziz ${ }^{2 *}$, and Ehab K. I. Hamad ${ }^{1}$ \\ ${ }^{1}$ Dept. of Electrical Engineering, Faculty of Engineering, Aswan University, Aswan 81542, Egypt \\ ${ }^{2}$ Dept. of Electronics \& Comm., Luxor Higher Institute of Engineering \& Technology, Luxor 85834, Egypt \\ Corresponding author: (e-mail: d20190014@aswu.edu.eg).
}

\begin{abstract}
A new design of a multiband microstrip patch antenna using slots in the patch as well as defected ground structures (DGS) implemented in the ground plane is proposed. Multi resonance response was obtained by etching the DGS shapes in the ground plane of a traditional patch operates at $5.2 \mathrm{GHz}$, which is the common frequency for the Internet of Things (IoT) applications. The novel outcome of this work is a compact antenna that resonates at three bands, viz. 2.42, 5.22 and $5.92 \mathrm{GHz}$. Different shapes of slots were used to improve the antenna performance at the different resonances. The antenna uses the inset feeding technique to improve impedance matching. Rogers RO3003 substrate of 3 relative dielectric constant, 0.0013 loss tangent, and $1.5 \mathrm{~mm}$ thickness is used to build the antenna. The designed antenna is simulated using HFSS software. The good consistency between simulations and measurements confirms the antenna's ability to improve the benefits for IoT applications at three different frequencies.
\end{abstract}

INDEX TERMS: Multiband antenna, DGS, Internet of Things, IoT, Slotted patch

\section{INTRODUCTION}

Rapid evolution of communications and the ever-increasing demand for wireless access have the world focused on proper utilization of the sub-GHz band for the design of antennas that fit smaller devices and that provide wider bandwidth [1]. The Internet of Things (IoT) encompasses major progress in computer networking, microelectronics and contemporary communication systems. This technology enables the remote control of physical sensors and actuators over the internet. These devices must be compact, economical and energy efficient to operate on the multiband for LTE, WLAN (IEEE $802.11 \mathrm{a} / \mathrm{b} / \mathrm{g} / \mathrm{n}$ ), WiMAX (IEEE 802.16), ZigBee (IEEE802.15.4) and GSM $(800 \mathrm{MHz}, 850 \mathrm{MHz}$, and $1900 \mathrm{MHz})$ [2]. In order to ensure reliable communication. The IoT reporting on these categories is reflected in the increase in the world population and the number of connected devices. The world's population in 2003 stood at 6.3 billion people with 0.08 percent linked equipment per person, while these figures were increased respectively to 7.2 billion and 3.4 percent in 2015. It is anticipated that this trend will grow exponentially, which will increase the demand for smaller devices along with the better antenna module. Owing to miniaturization of embedded systems, multiple modules can be installed on these small gadgets in order to improve efficiency, reliability and strength to fit different environmental scenarios, intelligent cities, intelligent health care, smart grids, military / security, etc. [3].

Narrow bandwidth and low gain are considerable problems of microstrip patch antennas that restrict their applications.
There are various bandwidth and gain enhancement techniques such as loading of different slot shapes and sizes [4], notches on the patch or in the ground plane and the adoption of metamaterials (MTM) in their fabrication [5]. A U-shape structure is being used for designing a microstrip patch antenna with resonating frequency in the range of $\mathrm{S}$ band, various slot shapes are used to shift the resonating frequency range to L-band [6]. Another microstrip patch antenna is modified in two steps: first by adding two rook slots to the patch plane and second by two semi ellipses on both bottom edges of the radiating element [1]. A number of researchers have reported microstrip patch antennas for IoT applications such as a microstrip line fed truncated icosidodecahedron modeled antenna [7]. Also, etching defected ground structures (DGS) of a simple shape in the ground plane, or a complicated shape for the better performance $[8,9,10]$, and use of a metamaterial split ring resonator $[11,12]$ have been reported in recent literatures. This paper describes a new design of microstrip patch antenna where a DGS was loaded on the ground plane to generate multiple resonance frequencies for different applications in IoT bands. Additional slots with various shapes were introduced in the conventional patch to increase the initial patch resonance. The position and dimensions of the modifications were set to obtain minimum return loss and the highest possible gain. The conventional patch antenna was chosen as a reference antenna to operate at $5.2 \mathrm{GHz}$ for IoT band applications. The designed antenna was optimized to resonate at the Bluetooth, Zigbee and Wi-Fi bands (2.42, 5.22 and 5.92 $\mathrm{GHz}$ ). Simulations and experimental measurements were carried out for verification and confirmation of the designed antenna where good agreement between the results served as validation. 


\section{ANTENNA CONFIGURATION}

We present, first, a DGS inspired rectangular microstrip patch antenna. A traditional $5.2 \mathrm{GHz}$ patch antenna was selected as a reference antenna for the first time. The designed reference antenna has a width and length of 15.75 and $25.5 \mathrm{~mm}$, respectively, and a copper thickness of 35 $\mu \mathrm{m}$. The patch radiator has been printed on a $1.5 \mathrm{~mm}$ thickness substrate $(\varepsilon r=3, \tan \delta=0.0013)$ of Roger Ro 3003 as displayed in Fig. 1(a). A $50 \Omega$ microstrip inset feed of $3 \mathrm{~mm}$ width and $12 \mathrm{~mm}$ length was introduced to perfectly matching the antenna. The feed line was inset to the patch with a value of $Y_{0}=3.5 \mathrm{~mm}$. The inset feed line was separated from the patch by two gaps, viz. $W_{01}=2.5$ $\mathrm{mm}$ and $W_{02}=0.5 \mathrm{~mm}$ as shown in Fig. 1(a). The reference antenna was optimized for a reasonable gain of $7.86 \mathrm{~dB}$. The reflection coefficient, $\mathrm{S}_{11}$ of the antenna is depicted in Fig. 1(b) where it can be observed that the antenna resonated at $5.2 \mathrm{GHz}$.

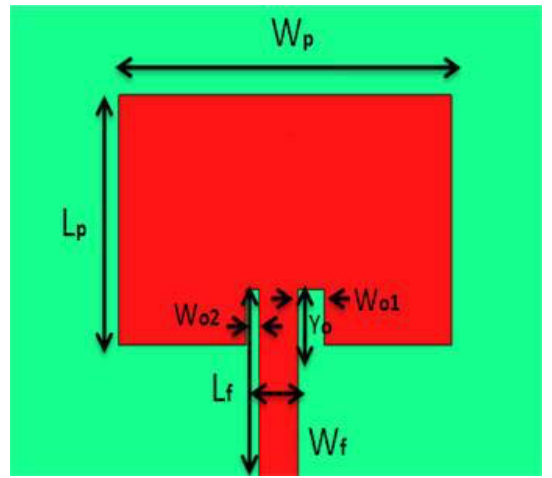

(a)

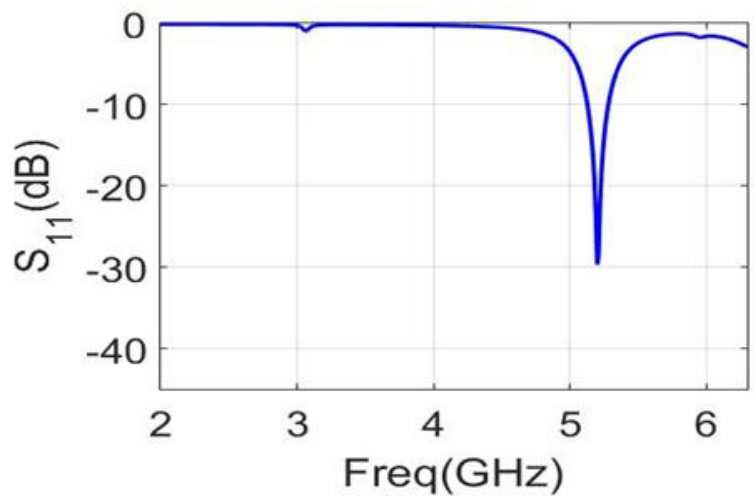

(b)

FIGURE 1. Conventional microstrip antenna operating at $5.2 \mathrm{GHz}$ (a) Schematic diagram, (b) Simulated S11 parameter

\section{A. Development of the Proposed Antenna}

Different developmental stages of the proposed antenna are shown in Fig 2(a) to (c). Initially in Stage 1, two nested gaped-rectangular slots were implemented as a defected ground structure in the ground plane to create additional resonant frequencies. The selected position of the DGS was dependent on the current distribution within the ground plane. The dimensions of the DGS were optimized to set the resonant frequencies at the desired frequency bands and to minimize the reflection coefficient $\left(\mathrm{S}_{11}\right)$. The parametric study in this stage indicated how the size of the DGS affected the resonance frequencies and the $S_{11}$ result, as shown in Fig. 2(d), to determine the definite size of the
DGS for proper operation. Additional DGS in the next stages were intended to improve the performance of the antenna at the specific resonant frequency created above. Stage 2 had the objective of improving the reflection coefficient of the first resonance at $2.4 \mathrm{GHz}$. This was done by etching two nested U- and L-shaped slots at the top-left and bottom-right corners of the radiating element. The positions of the two slots at the edges of the patch were chosen based on the concept of fringing fields. The resulting antenna worked well, showing good performance at 2.4 GHz. In Stage 3, an additional E-shaped slot was etched in the patch as illustrated in Fig. 2(c). This slot was optimized to improve considerably the antenna performance at the three resonant frequencies at 2.4, 5.19 and $5.9 \mathrm{GHz}$ for IoT applications. All three stages were simulated, and the reflection coefficients are displayed in Fig. 2(d).

The boundaries had to be set as shown in Fig. 3 to verify and to extract the scattering parameters of this proposed antenna. Perfect magnetic conductor (PMC) boundary conditions were set on the left and right walls of the air box, and perfect electric conductor (PEC) boundary conditions were set on the top and bottom of the air box [13]. In order to identify the resonant frequencies and the effective parameters derived from DGS and slot, scattering parameters were calculated over an acceptable frequency range. The E-field of the incident wave was polarized along the $\mathrm{z}$-axis, and the $\mathrm{H}$-field was polarized along the $x$-axis [14]. The optimal dimensions of the designed antenna, DGS as well as the slots are listed in Tab. 1. The incident TEM wave propagated in the direction of the $y$-axis.

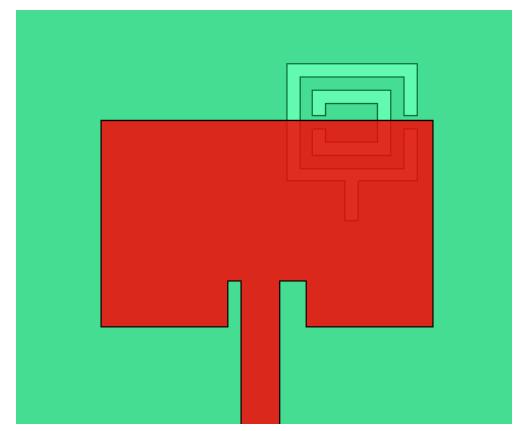

(a)

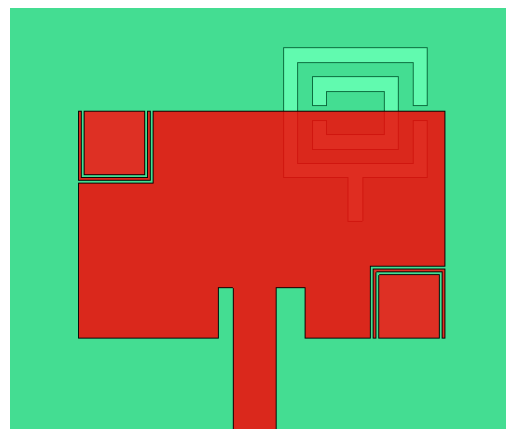

(b) 


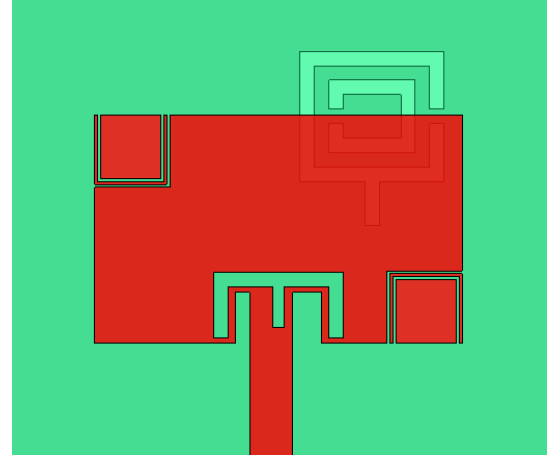

(c)

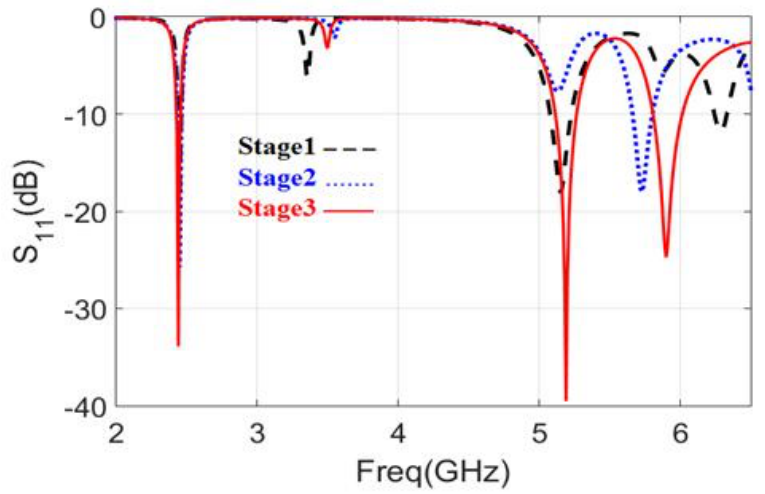

(d)

FIGURE 2. Development of proposed antenna. (a) Stage 1, (b) Stage 2, (c) Stage 3, and (d) S-parameters of different stages.

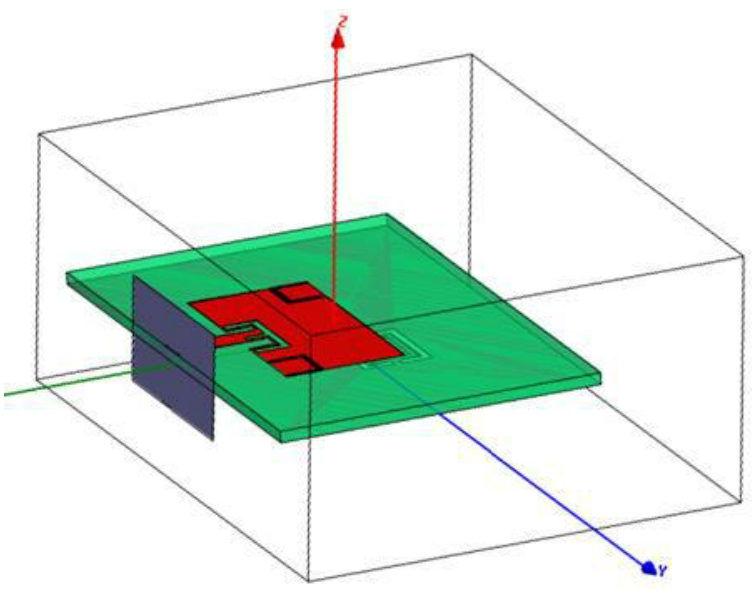

FIGURE 3. Microstrip patch setup for transmission analysis.

\section{B. DGS and Slots}

This section describes in detail the influence of the geometrical parameters of the DGS implemented in the ground plane and of the slots implemented as a radiating element on the antenna performance. The aim of etching the DGS in the ground plane was to create additional resonant frequencies at $2.44 \mathrm{GHz}$ and $5.9 \mathrm{GHz}$. The schematic diagram of the rectangular DGS is shown in Fig. 4(a). The objective of adding two different shapes of slots into the radiating element was to achieve good performance of the proposed antenna at the three resonant frequencies. The schematic diagrams of the proposed slots are shown in Fig. 4(b) and (c). Optimized values of the proposed antenna dimensions including the created DGS and slots are listed in Table I.

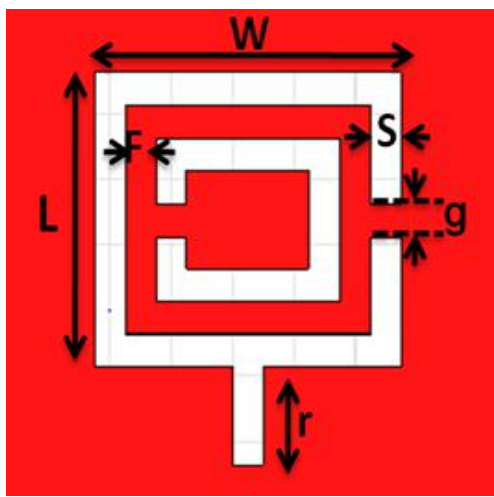

(a)

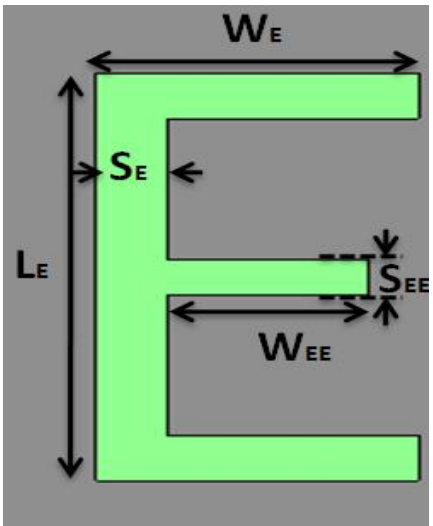

(b)

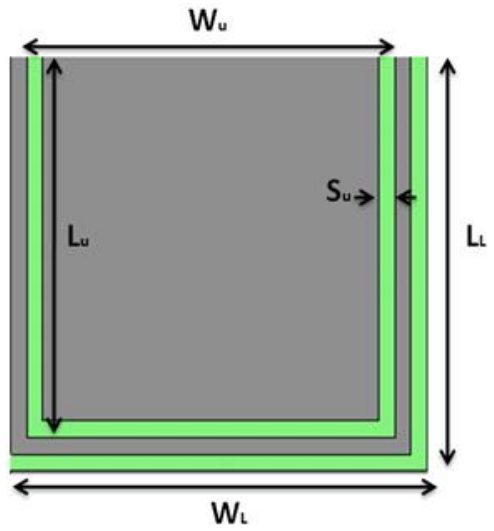

(c)

FIGURE 4. Schematic diagrams of the (a) Rectangular DGS, (b) E-slot in the patch of antenna, and (c) U-L-slots in the patch of antenna 
TABLE I. Optimal values of the proposed antenna parameters

\begin{tabular}{cccc} 
Parameter & Value $(\mathrm{mm})$ & Parameter & Value $(\mathrm{mm})$ \\
\hline$L_{p}$ & 15.75 & $r$ & 3 \\
$w_{p}$ & 25.5 & $g$ & 1 \\
$L_{f}$ & 12 & $w_{E}$ & 4.5 \\
$w_{f}$ & 3 & $L_{E}$ & 9 \\
$w_{o 1}$ & 2.5 & $S_{E}$ & 1 \\
$w_{\mathrm{O} 2}$ & 0.5 & $S_{E E}$ & 0.8 \\
$Y_{o}$ & 3.5 & $w_{E E}$ & 2.8 \\
$L$ & 9 & $w_{u}$ & 4.6 \\
$w$ & 10 & $L_{u}$ & 4.6 \\
$s$ & 0.2 & $S_{u}$ & 0.2 \\
$F$ & 1 & $L_{L}$ & 5 \\
$w L$ & 5.2 & &
\end{tabular}

\section{PARAMETRIC STUDY}

A full parametric study was carried out in order to examine the effects of the geometrical variables in the proposed design in order to identify evaluation parameters, determine each parameter range, define design limitations and analyze the result of each parameter variation. Once configurations were developed, our simulations were tested before the parameters were further refined according to design constraints until the results were satisfactory. First of all, the feeding line location was designed to perfectly match the transmission line to the patch. The center of the patch is taken as a reference point for all axes $(x=0, y=0)$. The ground plane length was then modified so as to reach the widest bandwidth possible. The optimized design without further development is illustrated in Fig. 1. Each DGS and slot form has subsequently been individually studied.

\section{A. Defected Ground Structure}

The commonly used structures of metamaterial are Split Ring Resonators (SRRs) and Complementary Split Ring Resonators (CSRRs). The effects of inserting CSRR in the ground plane of a microstrip patch antenna on the return loss, radiation pattern and magnetic field were evaluated with respect to the variations in the CSRR dimensions [15]. Metamaterial structures can be designed in many ways and the introduction of DGS on the ground plane effectively increases the inductance and capacitance of the overall electric circuits [16]. In the present study, DGS was incorporated in the ground as illustrated in Fig. 2(a) to provide a satisfactory response for the new resonant frequencies. The CSRR structure shown in Fig. 4(a) is modified by incorporating an open-circuited stub joint to that CSRR. The influence of the position where the stub is joint; left, right or centered on the edge of the CSRR in terms of the reflection coefficient are investigated in Fig. 5.

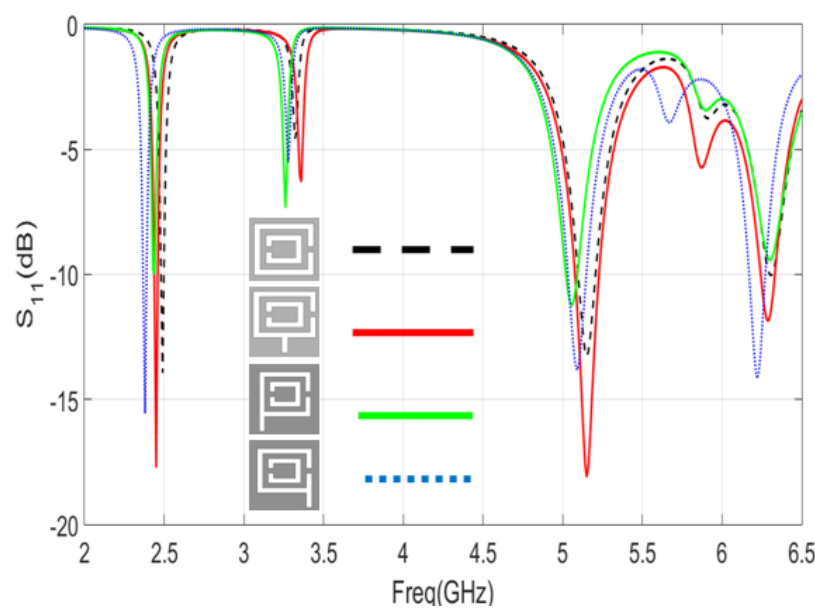

FIGURE 5. S-parameters of CSRR and DGS where the stub is jointed to the CSRR

\section{B. U- and L-Shaped Slots}

The parametric study in this stage shows how the position of $U$ and $L$ slots (keeping their dimensions constant) would affect the resonant frequency at $2.45 \mathrm{GHz}$ to determine the best position for proper operation of the slots. The placement of the slots inside the patch varied from $x=-2.8$ $\mathrm{mm}$ to $12.8 \mathrm{~mm}$ along $x$-axis direction where $x=0, y=0$ was the reference point where the patch was centered. For the $y$-direction, the best position of the slots at the edges of the patch was selected based on the fringing field theory. The design of the patch with DGS could only achieve 1.5 $\mathrm{dBi}$ peak realized gain, so $U$ and $L$ slots were used in order to much enhance the reflection coefficient and the gain at $2.45 \mathrm{GHz}$. It should be noted that the parametric studies at this stage were carried out twice, alternately for slots on the right side and then on the left side. The best location of slots on the right side in $x$-direction was at $x_{r}=12.8 \mathrm{~mm}$ and the optimal value obtained on the left side was at $x_{l}=-2.8$ $\mathrm{mm}$.

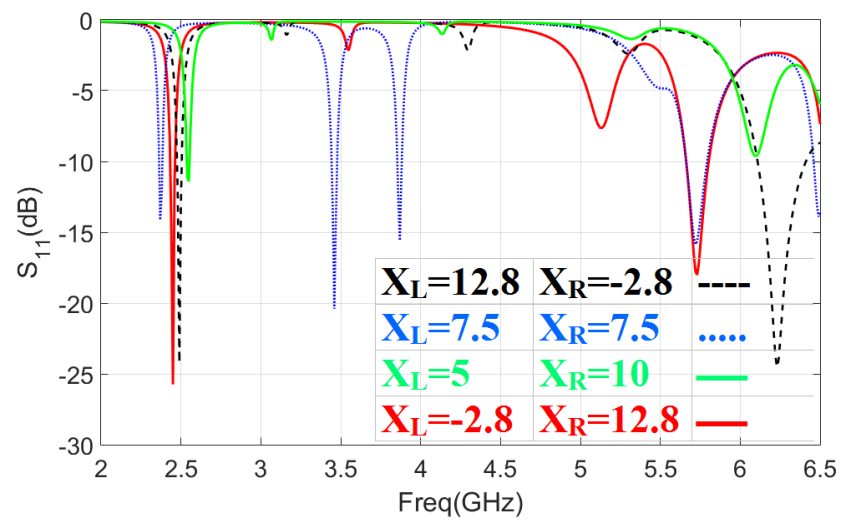

FIGURE 6. Parametric study for the second stage, operating at $2.45 \mathrm{GHz}$, positioned in the $\mathrm{x}$ direction 


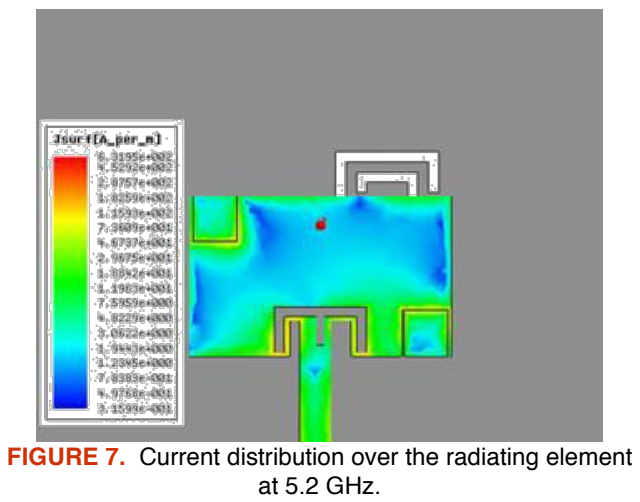

\section{E-Shaped Slots}

An additional, E-shaped slot etched within the radiating patch to further improve the S-parameter at the second resonance $(5.2 \mathrm{GHz})$ was introduced. The position of the Eshaped slot based on the current distribution was optimized to a location closer to the feed line as depicted in Fig. 2(c). Figure 7 shows the current distribution over the radiating element at 5.2 GHz. Figure 2(c) illustrates how the U and E slots were etched in the design. The simulated return loss of this step is displayed in Fig. 2(d).

\section{SIMULATION RESULTS}

All slots were integrated in the radiating element and the DGS in the ground plane as shown in Fig. 2(c) to optimize impedance matching at all resonances and, hence, the performance of the final design in achieving the triple band behavior. The proposed antenna was simulated using the 3D EM full-wave simulator HFSS according to the finite element method. The reflection coefficient and the voltage standing wave ratio (VSWR) of the proposed antenna are illustrated in Fig. 8(a) and (b), respectively. As observed from the figures, the designed antenna operated at three resonant frequencies, viz. 2.44, 5.19, and $5.9 \mathrm{GHz}$ suited for IoT applications. The optimized reflection coefficients magnitudes were less than $-33.9 \mathrm{~dB}$ at $2.44 \mathrm{GHz}$, less than $39.5 \mathrm{~dB}$ at $5.19 \mathrm{GHz}$ and less than $-24.7 \mathrm{~dB}$ at $5.9 \mathrm{GHz}$. The VSWR was very close to one at the three resonances of interest.

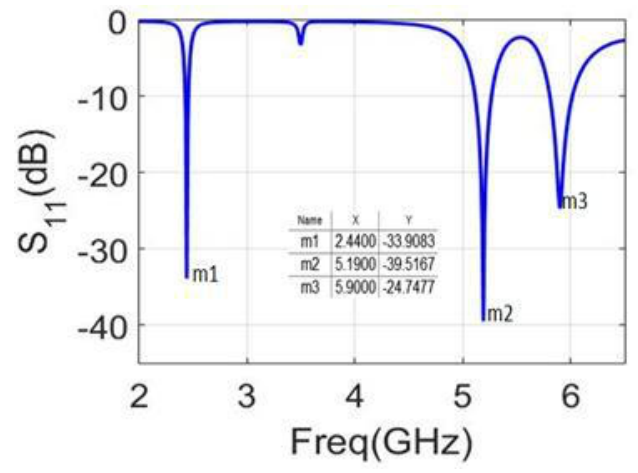

(a)

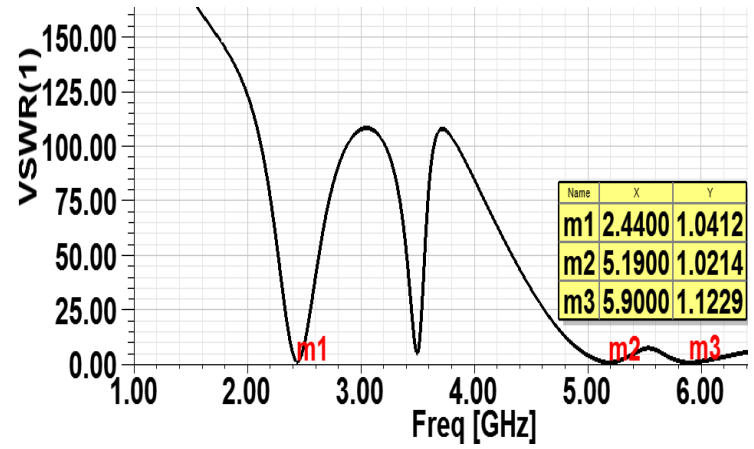

(b)

FIGURE 8. EM simulation results of the proposed final design, (a) S11, and (b) VSWR

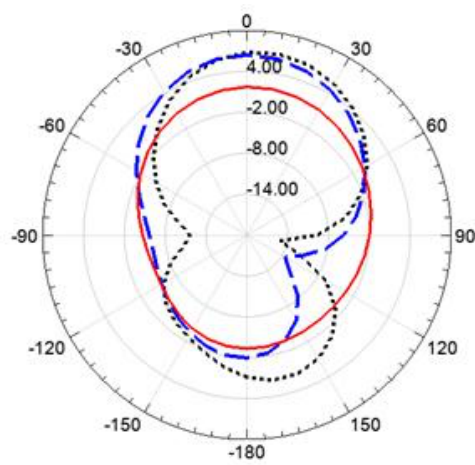

(a)

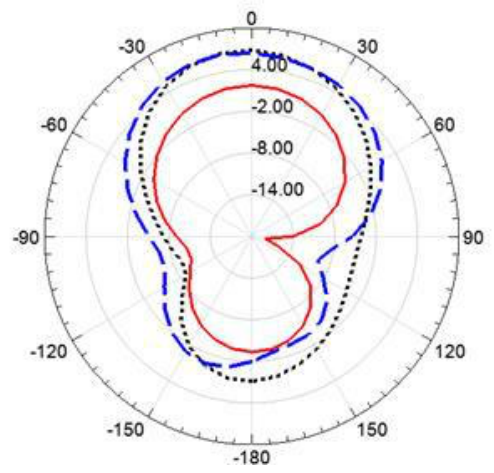

(b)

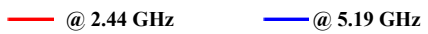

- $5.9 \mathrm{GHz}$

FIGURE 9. Radiation pattern of the proposed antenna at (a) $\mathrm{phi}=0^{\circ}$, and (b) phi $=90^{\circ}$ 


\section{FABRICATION AND MEASUREMENTS}

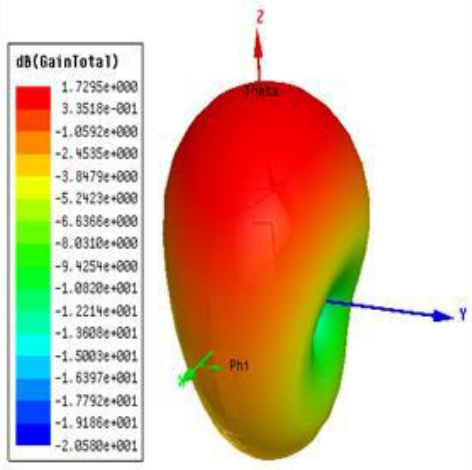

(a) at $2.44 \mathrm{GHz}$
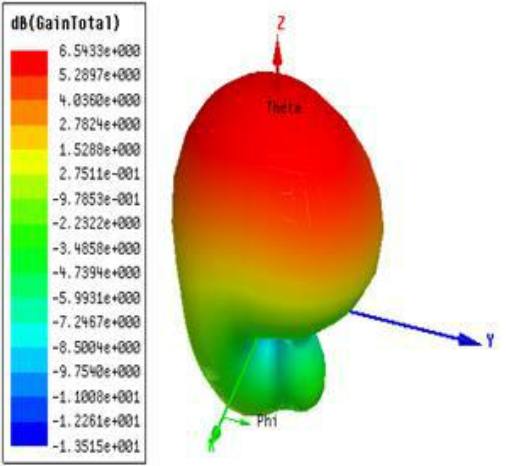

(b) at $5.19 \mathrm{GHz}$

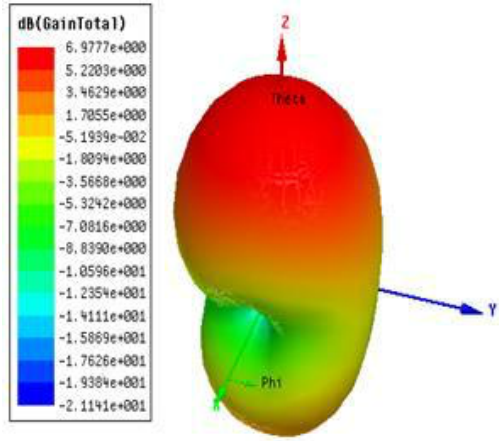

(c) at $5.9 \mathrm{GHz}$

FIGURE 10. 3-D polar plots of the gain of the proposed antenna at the resonant frequencies.

The radiation patterns at the E- and H-planes of the proposed antenna are almost quasi-Omnidirectional radiating patterns at $2.44,5.19$ and $5.9 \mathrm{GHz}$. The simulated results are displayed in Fig. 9 (a) and (b). As observed from the graphs; the radiation patterns at the three resonance frequencies were quite similar in terms of stability impression. In Fig. 10, the 3D polar plots of the antenna gain at the three resonant frequencies are illustrated. It is apparent that the directivity of the proposed antenna would make it a good candidate for IoT applications.
The proposed triple-band antenna was fabricated and tested to validate the simulation results. A photograph of the measurement setup is shown in Fig. 11(a) where the antenna is connected to a vector network analyzer (VNA) to measure the S-parameters and the VSWR. Photographs of the prototype for the fabricated antenna with triple-band response for IoT applications are shown in Fig. 11(b). Fig. 11(c) depicts the measured S-parameter compared to the EM simulation. It can be observed that the fabricated model resonates at 2.42, 5.22 and $5.92 \mathrm{GHz}$. The measurement results were fairly consistent with the simulated results as shown in the comparison summarized in Table 2.

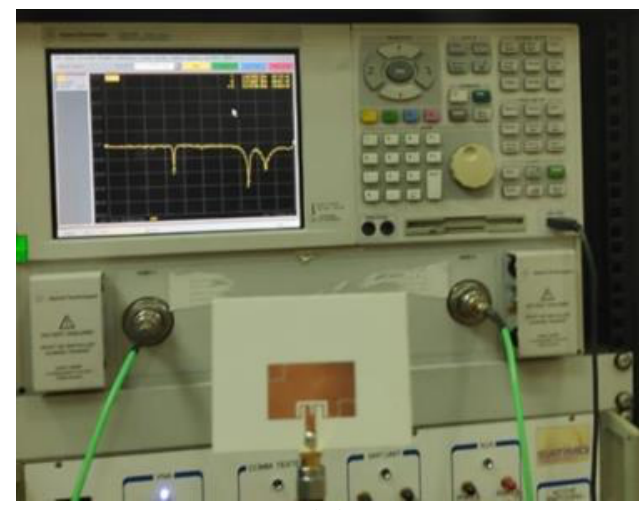

(a)
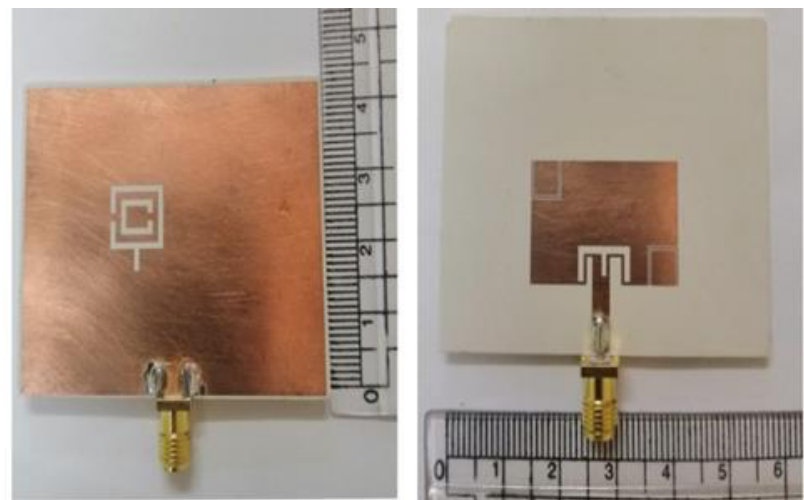

(b)

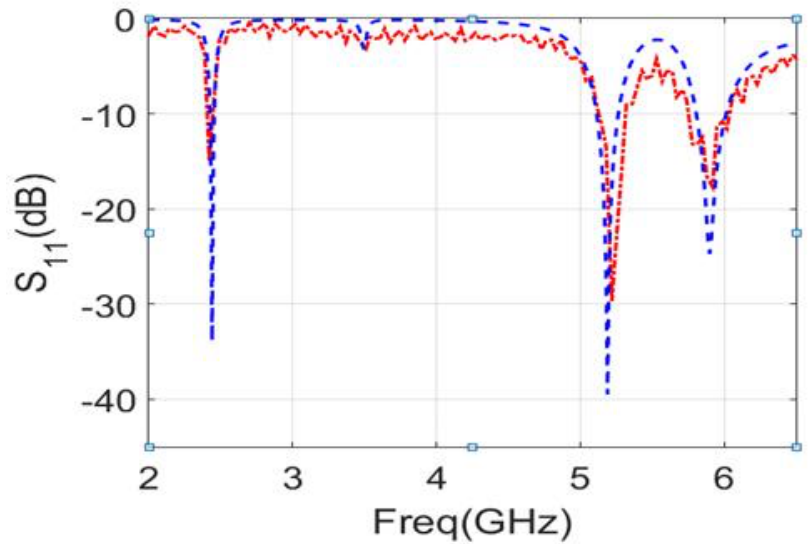

(c)

FIGURE 11. (a) Measurement setup, (b) Top and bottom views of the prototype, (c) Measured and simulated S-parameters 
TABLEI I.: Comparison between simulated and fabricated antenna

\begin{tabular}{|c|c|c|c|c|c|c|c|}
\hline \multirow[b]{2}{*}{ Resonant Frequency GHz } & \multirow{2}{*}{$\begin{array}{c}\text { Reference } \\
\text { antenna }\end{array}$} & \multicolumn{3}{|c|}{$\begin{array}{l}\text { Proposed antenna } \\
\text { (Simulations) }\end{array}$} & \multicolumn{3}{|c|}{$\begin{array}{l}\text { Proposed antenna } \\
\text { (Measurements) }\end{array}$} \\
\hline & & 2.44 & 5.19 & 5.9 & 2.42 & 5.22 & 5.92 \\
\hline $\mathrm{S}_{11}$ & -29.7 & -33.9 & -39.5 & -24.7 & -14.9 & -29.7 & -17.7 \\
\hline Gain(dB) & 7.86 & 1.72 & 6.54 & 6.97 & 2.48 & 7.17 & 8.18 \\
\hline
\end{tabular}

As seen in Fig. 12 the measured radiation pattern of E- and $\mathrm{H}$-planes of the proposed antenna at the three frequencies are mostly Omni-directional patterns with little ripples.

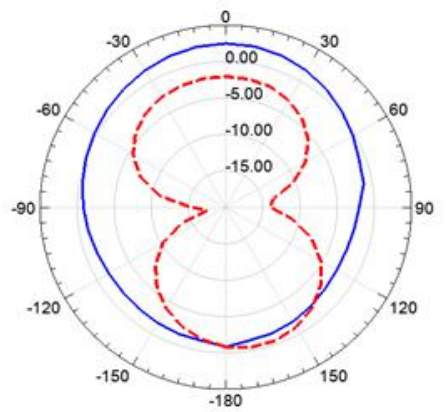

(a) E \& $\mathrm{H}$ planes at $2.42 \mathrm{GHz}$

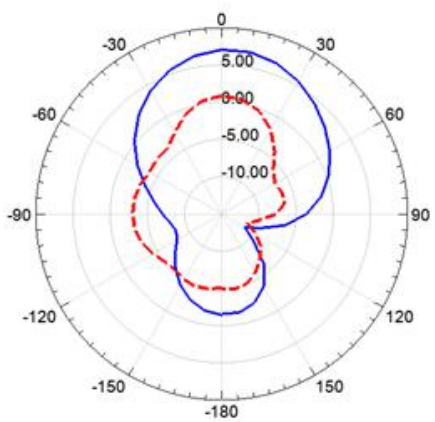

(b) E \& H planes at $5.22 \mathrm{GHz}$

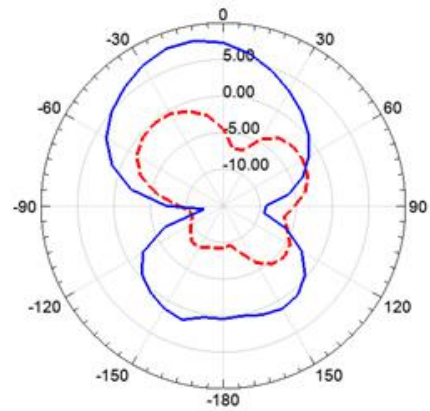

(c) E \& $\mathrm{H}$ planes at $5.92 \mathrm{GHz}$

_ E plane ---- H Plane

FIGURE 12. Measured E- and $\mathrm{H}$-planes radiation patterns at the three frequencies of the triple band antenna.

Table III presents a comparison of the proposal antenna with the other literature designs in terms of operating frequencies, peak gain and size for determining the validity of the proposed triple-band antenna. This comparison indicates that the proposed antenna is more beneficial than other antennas, although in some cases the current design is smaller.
TABLE III. Comparison of the proposed antenna with other prototypes

\begin{tabular}{llll}
\hline Ref. & $\begin{array}{l}\text { Operating } \\
\text { frequency }(\mathrm{GHz})\end{array}$ & $\begin{array}{l}\text { Peak } \\
\text { gain(dBi) }\end{array}$ & Dimensions $(\mathbf{m m})$ \\
\hline$[5]$ & $\begin{array}{l}0.78,2.41,3.22, \\
4.83,5.83\end{array}$ & 7.44 & $110 \times 90 \times 6.35$ \\
& $\begin{array}{l}\text { 1.8,5.2, } \\
{[17]}\end{array}$ & 1.52 & $30 \times 20 \times 1.52$ \\
& $7.86,8.53$ & & \\
{$[18]$} & $2.38,1.53$ & 2.5 & $110 \times 65 \times 1.6$ \\
This & $2.42,5.22,5.92$ & 8.18 & $55.5 \times 42.75 \times 1.5$ \\
work & & & \\
\hline
\end{tabular}

\section{CONCLUSION}

This paper proposed a triple-band antenna for IoT applications. It is designed and constructed based on DGS and slots structure techniques. The proposed antenna is compatible with Bluetooth, WLAN, Wi-Fi, Zigbee and other standards of the IoT system. The effects of the DGS and slots on the antenna performance are greatly depending on the position within the radiating element. The antenna was printed on the low loss Rogers Ro3003 substrate of $\varepsilon_{\mathrm{r}}=$ $3-$, and $1.5-\mathrm{mm}$ thickness. Good matching between the measured and simulated results was achieved.

\section{ACKNOWLEDGMENT}

The authors would like to thank Eng. Nagdy of the NTI Institute, Cairo, Egypt, for his help in fabricating the proposed models. Thanks go also to Eng. Mohamed Abdelaziz for his support in the measurements of radiation characteristics of the fabricated models at the Science and Technology Center of Excellence in Cairo, Egypt.

\section{References}

[1] M. Mokayef, M. A. Summakieh, "An Ultra-Widwband for IoT Connectivity," International Journal of Internet of Things and Web Services, Vol .2, pp. 76-79, 2017.

[2] Q. Awais, H. T. Chattha, "A Novel Dual Ultrawideband CPW-Fed Printed Antenna forInternet of Things (IoT) Applications," Wireless Communications and Mobile Computing, Vol. 2018, pp. 1-9, Mar. 2018.

[3] D. Acharjya, M. K. Geetha, "Internet of Things: Novel Advances and Envisioned Applications," Springer International Publishing, 2017.

[4] A. Abdelaziz, E. K. I. Hamad, "Design of a Compact High Gain Microstrip Patch Antenna for Tri-Band 5G Wireless Communication," Frequenz, Vol. 73, Issue 1-2, pp. 45-52, January 2019. 
[5] E. K. I. Hamad, G. Nady, "Bandwidth Extension of Ultrawideband Microstrip Antenna Using Metamaterial Doubleside Planar Periodic Geometry," Radioengineering, Vol. 28, No. 1, pp. 25-32, April 2019.

[6] A. Satheesh, R. Chandrababu, and I. S. Rao, "A Compact Antenna for IoT Applications", IEEE, 2017 International Conference on tnnovations in Information, Embedded and Communication Systems (ICIIECS),17-18 March 2017, Coimbatore, India.

[7] V. Das, T. Shanmuganantham, "Design of Multiband Microstrip Patch Antenna For IOT Applications", IEEE International Conference on Circuits and Systems (ICCS), 20-21 Dec. 2017, Thiruvananthapuram, India.

[8] R. Er-rebyiy, J. Zbitou, A. Tajmouati, M. Latrach, A. Errkik, and L. El Abdellaoui, "A New Design of a Miniature Microstrip Patch Antenna Using Defected Ground Structure DGS", International Conference on Wireless Technologies, Embedded and Intelligent Systems (WITS), 19-20, April 2017, Fez, Morocco.

[9] B. T. P. Madhav, S. Rajiya, B. P. Nadh, and M. S. Kumar, "Frequency reconfigurable monopole antenna with DGS for ISM band applications," Journal of Electrical Engineering, Vol 69, no. 4,2018.

[10] L. Wu, F. Wan, W. Rahajandraibe, S. Lalléchère and B. Ravelo, "On the investigation of contactless bandpass NGD control with microstrip patch-based circuit," Journal of Electromagnetic Waves and Applications, Vol. 34, no. 14, pp. 1849-1857, 2020.

[11] A. Sabban, "Small New Wearable Antennas for IOT, Medical and Sport Applications", IEEE 13th European Conference on Antennas and Propagation (EuCAP 2019), 31 March-5 April 2019, Krakow, Poland, Poland.

[12] P. Bora, C. Paul, "Metamaterial Loaded CSRR Based Antenna For WLAN And IOT BAND Applications", International Journal of Scientific \& Technology Research, Vol. 8, Issue 09, September 2019.

[13] W. Ali, E. K. I. Hamad, M. Bassiuny and M. Z. M. Hamdalla, "Complementary Split Ring Resonator Based Triple Band Microstrip Antenna WLAN/WiMAX Applications," Radioengineering, Vol. 26, No. 1, April 2017.

[14] E. K. I. Hamad and M. Z. M. Hamdalla,"Design of a Compact Dual-Band Microstrip Antenna Enabled by Complementary Split Ring Resonators for X-Band Applications", Advanced Electromagnetics, Vol. 7, No. 3, pp. 82-86, August 2018.

[15] I. B. T. da Silva, H. D. de Andrade, J. L. da Silva, "Effects of Complementary Split Ring Resonator (CSRR) Parameters in Microstrip Patch Antenna Characteristics",SBMO/IEEEMTTSInternational Microwav and Optoelectronics Conference (IMOC), 3-6 Nov. 2015, Porto de Galinhas, Brazil.

[16] V. G. Ajay, A. R. Parvathy, and T. Mathew, "Microstrip antenna with DGS based on CSRR array for WiMAX applications", International Journal of Electrical and computer Engineering (IJECE), Vol. 9, No. 1, Feb. 2019.

[17] S. K. Das, and T. Shanmuganantham, "Design of Triple Starfish Shaped Microstrip Patch Antenna for IoT Application", 2017 IEEE International Conference on Circuits and Systems (ICCS), 20-21 Dec. 2017. Thiruvananthapuram, India.

[18] P. Kumar, G. C. Ghivela, and J. Sengupta, "Design and Analysis of Multiple bands Spider Web Shaped Circular Patch Antenna for IoT Application", 2018 8th IEEE India International Conference on Power Electronics (IICPE), 1315 Dec. 2018, JAIPUR, India. 